DE

M E D I C I N A

T R O P I C A L

$\mathrm{DE}$

SÃO PAULO

JOURNAL OF THE SÃO PAULO INSTITUTE OF TROPICAL MEDICINE

${ }^{1}$ Canadian College of Microbiologists. Vancouver, British Columbia, Canada

${ }^{2}$ Centro Universitário INTA, Curso de Enfermagem, Sobral, Ceará, Brazil

${ }^{3}$ Universidade de Fortaleza, Curso de Medicina, Programas de Pós-Graduação em Saúde Coletiva e Ciências Médicas, Fortaleza, Ceará, Brazil

${ }^{4}$ Universidade Federal do Ceará, Faculdade de Medicina, Departamento de Medicina Clínica, Programa de Pós-Graduação em Ciências Médicas, Fortaleza, Ceará, Brazil

Correspondence to: Geraldo Bezerra da Silva Junior

Universidade de Fortaleza, Curso de Medicina, Programas de Pós-Graduação em Saúde Coletiva e Ciências Médicas, Av. Washington Soares, 1321, Bloco S, Sala S-01, CEP 60811-905, Fortaleza, CE, Brazil Tel: $+558534773280,+558534773424$

E-mail: geraldobezerrajr@unifor.br

Received: 27 March 2019

Accepted: 24 June 2019

\section{Kidney involvement in yellow fever: a review}

\author{
Renata Lima Lopes ${ }^{1}{ }^{[0}$, José Reginaldo Pinto², Geraldo Bezerra da \\ Silva Junior ${ }^{3}{ }^{\circledR}$, Artur Keyler Teixeira Santos ${ }^{2}$, Maria Taís Oliveira Souza², \\ Elizabeth De Francesco Daher ${ }^{4}$
}

\section{ABSTRACT}

Yellow fever is one of the most important mosquito-borne diseases, which still affects a significant number of people every year, mainly in tropical countries. Mortality can be high, even with intensive treatment due to multiple organ failure, including acute kidney injury (AKI). This disease can also be a burden on the health care system in developing countries, without mentioning the number of lives that could be spared with an early diagnosis and adequate monitoring and treatment. The pathophysiology of yellow fever-induced acute kidney injury (AKI) is still to be completely understood, and the best clinical approach has not yet been determined. This manuscript presents the most recent scientific evidence of kidney involvement in yellow fever, since AKI plays an important role in the mortality rate. Recent outbreaks have occurred in Brazil and further studies are required to provide a better clinical control for patients with yellow fever.

KEYWORDS: Yellow fever. Acute kidney injury. Epidemics. Pathophysiology.

\section{INTRODUCTION}

The genus Flavivirus, of the Flaviviridade family, is composed of some of the most pathogenic human viruses (Arboviruses), including Dengue virus (DENV), Yellow fever virus (YFV), Zika virus (ZIKV) and West Nile virus (WNV), among others $^{1-4}$. These are mosquito-borne diseases transmitted by the same hematophagous arthropod vectors, and their main hosts are vertebrate animals, with primates, humans and non-humans, as hosts ${ }^{1,3,5}$.

Yellow fever virus, the etiological agent of YF, belongs to the Flaviviridae family, genus Flavivirus, which are enveloped positive-sense single-stranded RNA viruses ${ }^{6-8}$. The production of a single polyprotein of the YFV occurs after the virus infects a host cell, thus beginning the translation of the viral genome. The thi protein is cleaved by the YFV proteases of the host, producing viral proteins that are essential for the virus genome replication and virion production ${ }^{7,9}$. A meticulous study of the yellow fever virus genome is essential to establish genetic differences between virus strains, helping the development of new treatments ${ }^{7,9}$.

In Brazil, there have been no reports on an urban cycle of the mosquito since 1942. However, the enzootic cycle (sylvatic yellow fever cycle involving non-human primates) occurs in the Amazon basin region ${ }^{8,10}$.

In the last two years, there has been a recrudescence of yellow fever (YF) in some countries in Africa and South America ${ }^{11}$, highlighting the need for effective tools and protocols against this arboviral disease, enhancing medical practices and public health policies in this field. As YF is not easily diagnosed, an adequate 
diagnosis constitutes the first line of defense. Laboratory confirmation of suspected cases of YF must be promptly performed, as it is imperative for the effective control of outbreaks and the prevention of disease dissemination ${ }^{12}$.

The severe viscerotropic disease caused by YFV has a high mortality rate, ranging from $25 \%$ to $50 \%^{13-15}$. The yellow fever virus is one of the most critical arboviruses. Annually, this virus is globally responsible for many new cases of disease (approximately 200,000) and some of them are fatal $(30,000 \text { deaths })^{2,14,16,17}$.

Yellow fever causes a pan-systemic febrile illness, with hepatic, renal and myocardial lesions. In more severe cases, internal hemorrhage, kidney failure, shock, coma or even death can occur ${ }^{11}$. In the most severe cases, the mortality rate is between $20-50 \%{ }^{15}$. Genetic factors seem to offer some protection, but according to Monath and Vasconcelos ${ }^{11}$, more studies are required to prove this hypothesis. Currently, specific antiviral treatment is not available for yellow fever (YF). Prevention and vaccination are the key control-factors in high-risk areas ${ }^{18}$. These areas are composed mainly of tropical forests in which the sylvatic cycle was first described in the 1930s and early $1940 \mathrm{~s}^{19,20}$.

A huge YF epidemic occurred in Rio de Janeiro/ Brazil between 1928 and 1929 ${ }^{21}$. However, since 1942, no other cases have been reported in the major Brazilian cities.

At the beginning of the $21^{\text {th }}$ century, new cases of yellow fever outside the rainforest environment have become a matter of concern for the Brazilian health authorities due to the expansion of the viral circulation area and the possibility of travelers carrying the virus to other countries ${ }^{21}$.

Some outbreaks and YF cases in non-epidemic areas have been reported. Since 2015, Brazil has faced significant sylvatic yellow fever outbreaks in the four States of the Southeast region, mainly due the insufficient vaccination coverage, since these States are not YF epidemic areas ${ }^{22,23}$. In addition, by the end of the $20^{\text {th }}$ century, the YF virus has spread to the Atlantic forest regions (Southeast and South of Brazil) increasing the number of infected primates and humans ${ }^{24}$.

YF urban outbreaks have been observed in Africa, as well. They occurred in December 2015, in Angola, and afterwards in the Democratic Republic of Congo in which persisted until January 2017, according to The World Health Organization (WHO) $)^{25-27}$. This 2015 outbreak in Angola was considered the most significant and widespread outbreak in Africa in more than 20 years $^{20}$. Furthermore, in 2016, an unconnected yellow fever outbreak took place in Uganda (Africa), and some occasional YF cases were reported in Chad, Ghana, Republic of Congo and Guinea later on, and, more recently, Nigeria has been facing an active yellow fever outbreak ${ }^{25-27}$.

\section{Historical aspects and epidemiology}

There is convincing evidence to the hypothesis that sylvatic YFV was introduced in the New World about four centuries ago, from West Africa to South America and the Caribbean during the slave trafficking period ${ }^{17}$. It seems that the YFV could only have been introduced through people presenting with viremia or by an infected vector (A. aegypti), as the yellow fever was very unusual on sailing ships ${ }^{3,28,29}$.

Since the 1950s, the transmission of YFV in the Americas occurred mainly through a sylvatic cycle involving primates and mosquitoes (Haemagogus and Sabethes genera). YFV is extremely pathogenic to primates and non-immune people ${ }^{24,29}$. The epizootic cycle, which is responsible for sylvatic cycle epidemics, appears in regular periods in some specific regions. Besides, the epizootic cycle may overlap sporadic yellow fever outbreaks in nonimmunized populations that live in or close to the forest ${ }^{24}$.

Globally, Fernandes et al. ${ }^{30}$ point out that the first probable exposure to YFV infection occurred 500 years ago, in 1585, in West Africa. Moreover, the first epidemic event was recorded in the $17^{\text {th }}$ century, when it was already considered a public health threat. Moreover, the dissemination of the YFV in Brazil was associated to trans-oceanic migrations, because these migrations brought the virus to Brazil and it has gradually spread out to the Northeast and Midwest regions ${ }^{30}$.

Locations such as Africa and the Americas are considered areas of YFV epidemic threat, due to their historical epidemic records even within the US ${ }^{31}$. Tretyakova et al. ${ }^{31}$ mentioned that the World Health Organization (WHO) has estimated that every year, 200,000 new cases of YF and 30,000 deaths will occur worldwide, even though the YF current geographic distribution includes mainly African and South American tropical areas.

Yellow fever sporadically disappears during the winter period $^{18}$. According to the Brazilian Ministry of Health and the $\mathrm{WHO}^{32,33}$, yellow fever is a seasonal disease that mostly occurs during the summer, with December and January being the hottest months in the Southern Hemisphere, when there is a higher number of confirmed cases, as shown in Figure 1.

Moreover, the Brazilian Ministry of Health published in February 2018 that 1,080 yellow fever cases were notified between July 2017 and January 2018, of which 213 were confirmed and 81 resulted in death ${ }^{32}$, as shown in Table 1.

The Brazilian Amazon basin is an epidemic area for yellow fever. However, sporadic outbreaks may occur outside this region, as shown in 2016, when thousands of yellow fever cases in humans were reported (more than $1,900)$ in Southeastern Brazil ${ }^{10}$. 


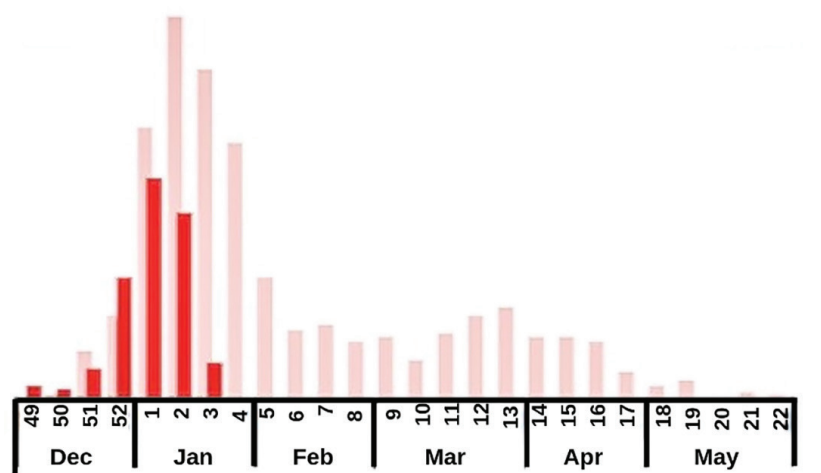

Seasonal Period

Monitoring 2017/2018

Monitoring 2016/2017

Figure 1 - Distribution of confirmed cases of yellow fever in Brazil in the seasonal monitoring period. Adapted from Ministério da Saúde ${ }^{32}$.

According to the revised 2010 yellow fever map, Brazil is one of the 11 South American countries within the YF endemic areas, and it is one of the seven countries where vaccination is required ${ }^{19}$.

Fernandes et $a l .{ }^{30}$ briefly explained how these massive outbreaks spread to areas outside the forest borders, by providing suitable environment for mosquitoes propagation in large Brazilian cities. If the YFV is circulating in the forest, primates can be infected, providing a new endemic area for sylvatic yellow fever. Therefore, the YFV moves forward through the forest areas, reaching cities that had been previously considered without risk of transmission ${ }^{30}$.

Because South America (particularly Brazil, Argentina, Paraguay, Bolivia, and Peru) and African regions have notified YFV circulation ${ }^{34}$, and the displacement of asymptomatic patients infected with yellow fever virus has implications for the global dissemination of yellow fever, it is imperative that travelers are vaccinated, due the high risk of yellow fever transmission ${ }^{23,25,33}$.

Table 1 - Distribution of reported yellow fever cases in Brazil, from July the $1^{\text {st }} 2017$ to January the $30^{\text {th }} 2018$.

\begin{tabular}{|c|c|c|c|c|c|c|}
\hline Region & $\begin{array}{l}\text { Brazilian states (probable } \\
\text { site of infection) }\end{array}$ & Notified & Discarded & $\begin{array}{c}\text { Under } \\
\text { investigation }\end{array}$ & Confirmed & Death \\
\hline \multirow{6}{*}{ North } & Amapa & 2 & 2 & 0 & - & - \\
\hline & Amazonas & 4 & 2 & 2 & - & - \\
\hline & Para & 23 & 13 & 10 & - & - \\
\hline & Rondonia & 5 & 5 & 0 & - & - \\
\hline & Roraima & 2 & 2 & 0 & - & - \\
\hline & Tocantins & 9 & 6 & 3 & - & - \\
\hline \multirow{6}{*}{ Northeast } & Bahia & 15 & 7 & 8 & - & - \\
\hline & Ceara & 1 & 1 & 0 & - & - \\
\hline & Maranhao & 1 & 1 & 0 & - & - \\
\hline & Pernambuco & 1 & 0 & 1 & - & - \\
\hline & Piaui & 3 & 1 & 2 & - & - \\
\hline & Rio Grande do Norte & 1 & 1 & 0 & - & - \\
\hline \multirow{4}{*}{ Midwest } & Distrito Federal & 27 & 18 & 8 & 1 & 1 \\
\hline & Goias & 26 & 16 & 10 & - & - \\
\hline & Mato Grosso & 1 & 0 & 1 & - & - \\
\hline & Mato Grosso do Sul & 5 & 3 & 2 & - & - \\
\hline \multirow{4}{*}{ Southeast } & Espirito Santo & 64 & 44 & 2 & - & - \\
\hline & Minas Gerais & 244 & 71 & 96 & 77 & 30 \\
\hline & Rio de Janeiro & 34 & 3 & 4 & 27 & 7 \\
\hline & Sao Paulo & 573 & 216 & 249 & 108 & 43 \\
\hline \multirow{4}{*}{ South } & Parana & 18 & 14 & 4 & - & - \\
\hline & Rio Grande do Sul & 11 & 4 & 7 & - & - \\
\hline & Santa Catarina & 8 & 2 & 6 & - & - \\
\hline & Total & 1,080 & 432 & 435 & 213 & 81 \\
\hline
\end{tabular}

Adapted from Ministério da Saúde ${ }^{32}$. 
Yellow fever was initially described only in Africa, and then the sailing ships carrying slaves accidentally transported mosquitoes and infected people to the South and Central Americas, where mosquitoes adapted to those regions due to climate similarities and expanded their natural habitat. Currently, the areas listed below, adapted from the $\mathrm{WHO}^{25,33,34}$ reports, show the yellow fever geographic distribution worldwide (Figure 2).

\section{Pathogenesis and clinical manifestations}

After the YFV-infected female mosquito bites, the virus infects dendritic cells within subcutaneous tissues and travels to the lymph nodes, where the virus replication occurs and the cellular immune response initiates. During this feeding process, approximately 1,000 to 100,000 viruses are inoculated into the host's bloodstream, starting the replication stage (since virus cannot replicate outside a host). After this first RNA virus replication cycle, viruses are released into the bloodstream through the lymphatic channels (viremia) and they spread firstly to the regional lymph nodes. Then, they leave the lymph nodes and reach different organs, especially the liver, heart and kidneys.

In humans, the wild-type YFV infection is mainly viscerotropic and affects firstly the liver, before damaging other tissues, including the kidneys, spleen, lymph nodes and heart. After the incubation period, the first infection phase ( $1^{\text {st }}$ stage) is characterized by a flu-like disease, during which fever is accompanied by chills, headache, nausea and myalgia. Then, a period of remission ensues, and most infected individuals recover. However, in the severe forms of YF, after a brief remission period ( $2^{\text {nd }}$ stage) of no more than $48 \mathrm{~h}$, some affected patients progress to the intoxication phase $\left(3^{\text {rd }} \text { stage }\right)^{27,33,35}$.

In this third stage (intoxication phase), the hemorrhagic and hepatic dysfunctions of this disease occur, and other multiple organ dysfunctions may also come along. The intoxication stage is severe and accompanied by symptoms characteristic of YF disease, including jaundice (which gave it the name of "yellow fever"), vomiting (black vomit or dark vomit, other ancient names of the disease) and other hemorrhagic manifestations such as vascular leakage ${ }^{8,27,36}$.

While the Haemagogus or Sabethes genera are the wild vectors, the Aedes aegypti mosquito, easily found in tropical cities, is the urban vector. A. aegypti is responsible for the dissemination of yellow fever in the urban environment. Therefore, the human-human transmission can occur when infected and non-infected humans are confined together, in the presence of a competent bridge represented by a domestic vector ${ }^{35}$.

The spectrum of clinical disease in humans is broad, and the severity of yellow fever can cause symptoms ranging from inapparent infection to severe forms with internal hemorrhage and acute hepatic and renal dysfunction. In

\section{Areas at Risk of Yellow Fever Transmission}

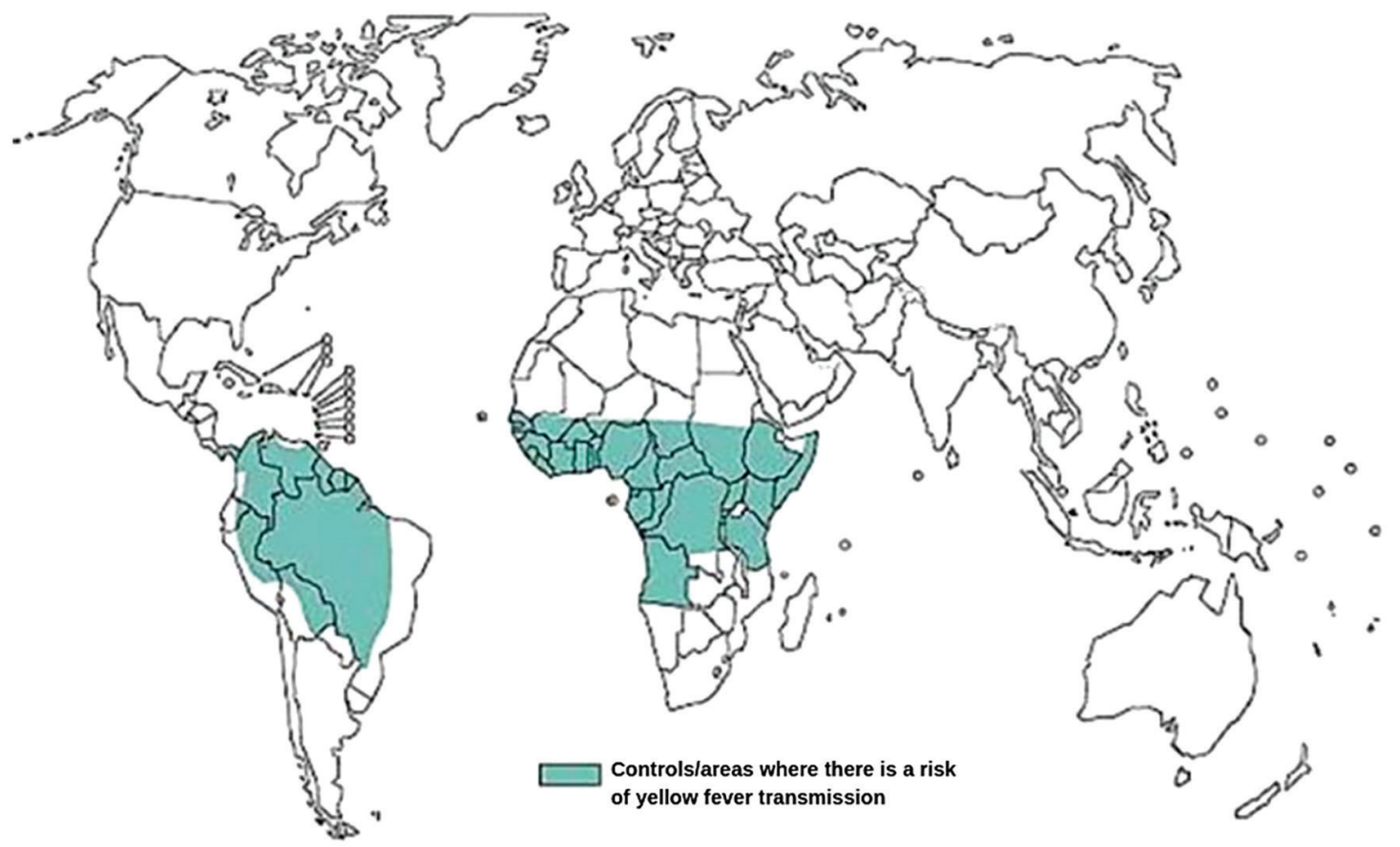

Figure 2 - Areas at risk of yellow fever transmission. Adapted from the World Health Organization ${ }^{34}$. 
humans, the YFV mainly affects the liver, promoting hepatic dysfunction and subsequently jaundice (yellowish skin). That was the reason the disease was named "yellow" fever, but other organs such as the heart, lymph nodes, spleen, kidneys and lungs are also viral replication sites ${ }^{35}$.

The initial symptoms are high fever, myalgia, low back pain, nausea and vomiting. Moreover, the evolution to the severe form of disease presenting with jaundice, hemorrhages, and, in some cases, multiple organ failure and shock may occur. Opportunistic diseases may also appear, and, according to Maciel et al. ${ }^{36}$, disseminated mycosis (severe infection in yellow fever patients) can mimic bacterial sepsis.

\section{Diagnosis and diagnostic methods}

One of the greatest challenges in yellow fever is the diagnosis of disease, because symptoms can be mistaken for other diseases such as respiratory, digestive or urinary infections ${ }^{37}$. Therefore, due the lack of symptoms specificity in the early stages of YF, the differential diagnosis is imperative, because yellow fever can be easily mistaken for other hemorrhagic diseases, such as leptospirosis, dengue fever, malaria and viral hepatitis ${ }^{2}$. Another important point is that YF shares the same vector and geographic areas of other tropical diseases, such as zika, dengue and chikungunya infections $\mathbf{s}^{1,5}$.

Additionally, the quick identification of zika, dengue and chikungunya viruses can indirectly help to control and prevent yellow fever, since the preventive measures to control the vector of these diseases will be the same ${ }^{1}$. Therefore, technological advances especially the molecular biology techniques, allow us to rapidly diagnose and differentiate diseases, and to be more assertive. To exemplify, there is a multiplex real-time PCR assay (RT-PCR) performed with primers and probes specifically designed to target and differentiate ZIKV, DENV, CHIKV and YFV ${ }^{1,5}$. Another method that can be used is a single real-time RT-PCR assay, but in this case RNA will be reverse transcribed and cDNA will be the target nucleic acid of these viruses, and this technique can be very helpful to manage outbreaks and control the spread of arboviral diseases ${ }^{1,2}$.

The YF laboratory diagnosis is attained through the detection of YF antigens by measuring IgM (which is not always representative of a recent infection) and IgG-specific antibody, when the patient has viremia ${ }^{3,4,14,33,38}$. To confirm the presence of YFV, it is necessary to use immunohistochemical techniques to detect YF antigens in tissues or nucleic acids detection using amplification methods, such as Mac-ELISA/IFA, PCR, RT-PCT or other immunoassays such as flow cytometry, and microscopic analysis $^{2-5,14,27,33,39,40}$. Laboratory investigation can also be performed by isolating the virus or its antigens in blood and tissue samples, or through the post-mortem histopathological analysis of tissues ${ }^{14,37}$, because the YF diagnosis is confirmed only through virus isolation (gold standard ${ }^{39}$. More recent molecular techniques, such as the Point of Care (POC), can also be used to have more accurate laboratory diagnoses, using a portable equipment ${ }^{2}$. Nevertheless, it cannot be used in developing countries due to the lack of investment in health care resources and laboratory equipment ${ }^{40}$. POC has been used to detect $\mathrm{ZIKV}$, CHIKV and DENV due its portability, specificity and sensitivity, using accessible samples such urine, saliva and tiny amounts of blood ${ }^{41}$. POC can be a great monitoring and diagnostic tool for yellow fever as well, because it can help to attain a faster diagnosis, being very specific, with a relatively low cost.

According to Zarei ${ }^{40}$, POC portability could benefit resource-limited regions even though there might be some barriers and challenges to overcome. However, the fact that it can be used in the field and not only in clinical settings is another reason that could help to attain a rapid diagnosis during outbreaks.

Other hemorrhagic diseases that constitute the differential diagnosis of yellow fever have been studied in search of bioactive molecules and toll-like receptors that can help to attain an accurate diagnosis ${ }^{41}$. This might indirectly help to diagnose YF when it is necessary to rule out other hemorrhagic infections that mimic it.

Cytokines can also be elevated, such as interleukin 6 (IL-6), interferon gamma-induced protein 10 (IP-10), monocyte chemoattractant protein 1 (MCP-1) and tissue necrosis factor alpha (TNF- $\alpha)^{14}$, but because they are immune-mediated and appear in inflammatory reactions, they are not specific for yellow fever.

Attaining a correct diagnosis is essential, especially if there are concomitant infections, because yellow fever can quickly evolve to the severe forms of the disease or even death $^{4,41}$.

\section{Kidney injury in yellow fever}

One of the targets for viral replication are kidney tissues. Some histological studies in non-human primates indicate that acute kidney tubular necrosis with protein cylinders and hemoglobin cylinders has some similarities with some classic histopathological findings of yellow fever in humans ${ }^{30}$. Maciel et al. ${ }^{36}$ described in details the kidney lesions observed in the autopsy of patients affected by the severe form of yellow fever virus infection, which was associated to disseminated mycoses. In addition, according 
to the study by Maciel et al..$^{36}$, interstitial nephritis was identified, associated with tubular necrosis and interlobular thrombosis in kidney vessels, as well as hemorrhage and ischemic necrosis of the adrenal gland.

The autopsy of another yellow fever patient showed that there was preservation of the parenchymal surface, showing only an irregular and hemorrhagic area in the upper pole of the left kidney, and a $1.5-\mathrm{cm}$ cyst on the anterior face of the right kidney. The microscopic analysis revealed multiple interstitial nephritis foci, combined with fibrosis and tubular necrosis. Thrombosis and intraluminal inflammatory infiltrates were identified in the vessels. The suggestive zygomycotic finding was characterized as a typical fungal hypha (pauci-septated hyaline fungal hyphae with a lateral right-angle formation) in the intravascular and interstitial inflammatory foci. Moreover, multiple foci of hemorrhagic lesions and necrosis in the left adrenal gland were microscopically identified, while the right adrenal gland was normal ${ }^{36}$.

Engelmann et al..$^{42}$ described granular bilirubin cylinders in the dilated distal convoluted tubules and protein cylinders in the kidneys of animals that needed euthanasia. Surprisingly, the yellow fever virus antigen was not detected in kidney tissues, which indicates no association with the virus replication site.

As discussed by Engelmann et $a l .^{42}$, the yellow fever disease follows the same pattern in monkeys as described in humans. However, it is more severe and develops faster in monkeys than in humans. Rhesus primates were sacrificed after the $5^{\text {th }}$ day of YFV infection and modifications in liver functions were detected up to $24 \mathrm{~h}$ before their death, whereas kidney abnormalities were only detected in the late stages of the disease ( 18 to $12 \mathrm{~h}$ before death) showing that these dysfunctions quickly led to death. Councilman bodies (areas of hepatocyte degeneration) and Torres bodies (intranuclear eosinophilic granular inclusions) have been demonstrated among post-mortem findings. Moreover, all kidney sections evidenced tubular necrosis and protein deposits that may lead to alterations in the kidney hemodynamics, renal azotemia and eventually, renal failure ${ }^{14,21,42}$.

In general, kidney dysfunctions appear between the fifth and seventh day of the disease, are characterized by the reduction of urinary volume and the urinary loss of albumin (a common blood protein). One frequent finding is a urinary volume lower than $500 \mathrm{~mL} /$ day, even if the patient is normovolemic, which may evolve to anuria and acute tubular necrosis (ATN). At this stage, there is a high rate of mortality. It is a fact that renal ischemia, intravascular coagulation, shock and tubular toxicity are induced by bilirubin and by direct effects of the virus on kidney tissues. If there is no improvement in kidney function, renal replacement therapy is indicated (peritoneal dialysis or hemodialysis $)^{43,44}$.

Although it is evident that there is damage in various organs such as the liver, kidneys and lymphoid tissue, viral antigens are only detected in the liver. According to Engelmann et $a l .{ }^{42}$, these observations provide new information on the yellow fever pathogenesis, suggesting that the kidney and the lymphoid tissue damage may not be directly mediated by in situ viral replication, probably occurring through soluble mediators that could be potentially produced elsewhere ${ }^{42}$.

The pathophysiology of yellow fever-associated acute kidney injury is illustrated in Figure 3.

Unfortunately, there is no available biomarker to measure the glomerular filtration rate and detect any kidney dysfunction accurately ${ }^{45}$.

Even though there are some widely used biomarkers to monitor the renal function in chronic diseases such as the levels of urea, creatinine, cystatin C, inulin, iothalamate and chromium-EDTA ${ }^{45,46}$, they are not helpful in yellow fever, because of the appalling disease severity and progression. According to the $\mathrm{WHO}^{33}$, if there is hepato-renal failure, up to $50 \%$ of the patients will die within 7 to 10 days, and those who do not die, may experience a long period of recovery from liver and kidney damages ${ }^{15}$. Consequently, these data highlights the importance of more studies on the kidney involvement in YF disease, because they are very important organs that are indirect targets of the disease, with severe consequences.

About 20 to $50 \%$ of death cases involving liver and kidney failure due to YFV is a significant high rate that should not be ignored. Additionally, renal supportive and palliative care procedures have high costs, and can compromise the health of patients living in developing countries since it will further burden the health budget of these countries. That makes this disease even more frightening than it could be, if the correct and early diagnosis, treatment and preventive measures are not adequately applied and are overlooked.

\section{Treatment}

To date, yellow fever treatment consists of intensive support by providing hydration, blood transfusions and, eventually, renal replacement therapy ${ }^{47}$. Some studies have shown that therapy remains limited to symptomatic care in hospitals, and, in the most severe forms of the disease, patients must be treated in intensive care units. Unfortunately, even though different molecules (polyclonal anti-YFV, target viral factors and immunomodulatory 


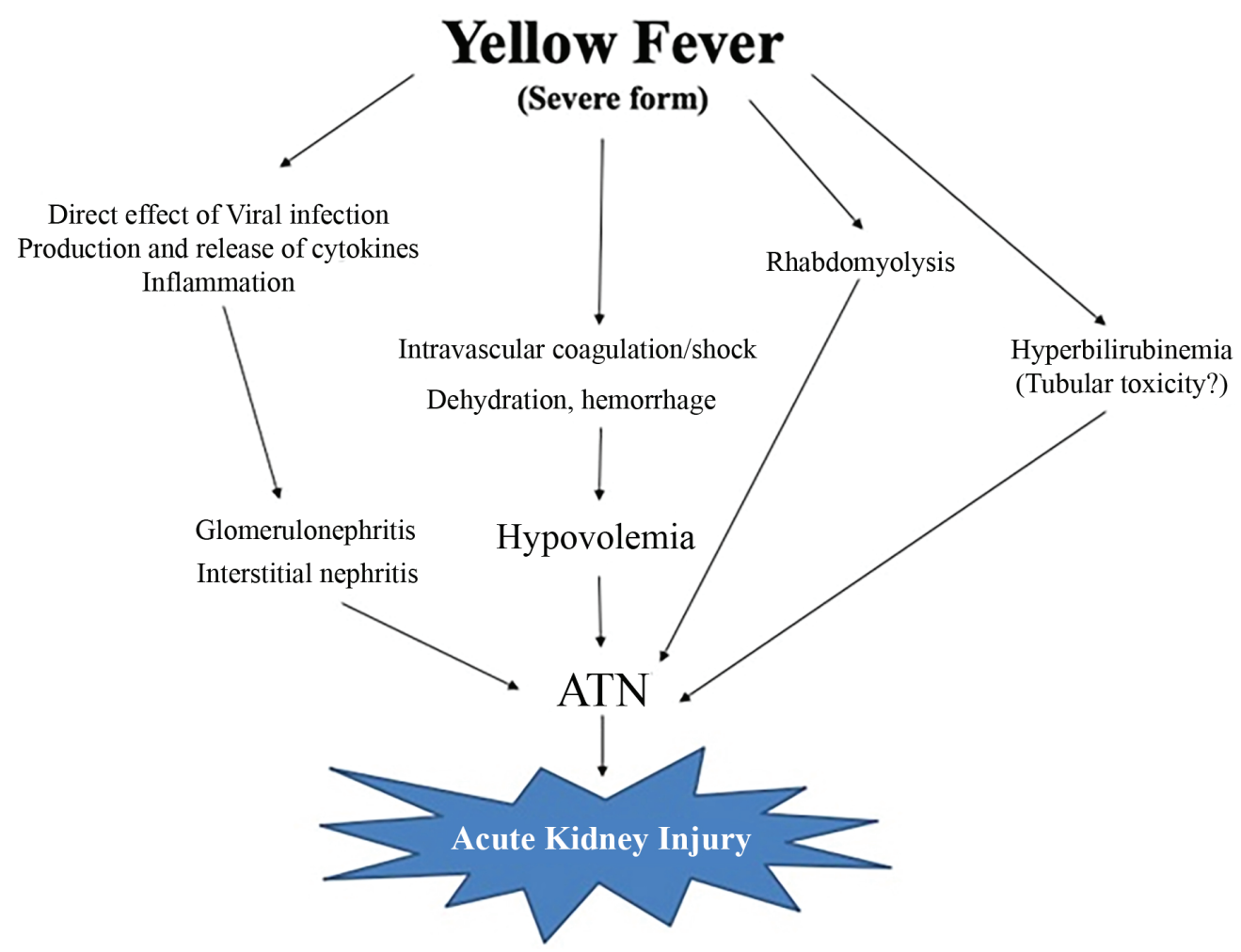

Figure 3 - Pathophysiology of yellow fever-associated acute kidney injury. Adapted from Daher and Silva Junior ${ }^{43}$.

compounds) have shown some activity against the virus, both in vitro and in vivo, they are not yet available for clinical use and have not been approved, as well ${ }^{14,35}$.

Currently, some new therapeutic options have been evaluated, including antiviral medication such as sofosbuvir. This drug is a direct antiviral inhibitor of the RNA-directed RNA polymerase (NS5B) enzyme of hepatitis C virus, which is essential for viral replication. This molecule incorporates into the RNA of hepatitis $\mathrm{C}$ virus and inhibits its replication. This drug is activated in hepatocytes, its prodrug is triphosphorylated and predominantly excreted by the kidney ${ }^{47,48}$.

Some mosquito-borne tropical diseases are deemed important and have been studied, aiming to apply nanotechnology for the production of new drugs to treat diseases such as dengue and malaria ${ }^{49}$. Nanotechnology aids in drug delivery, using biological organisms or nanoparticles (that can be made of metals such as gold) making drugs more disease-specific ${ }^{49}$. There are no nanodrugs been studied for YF yet, since it is a neglected disease, but there have been studies on nanopharmaceuticals for malaria, which shares the same vector as $\mathrm{YF}^{49}$.

\section{Prevention}

Since YF is a mosquito-borne disease, its eradication can be quite challenging, due to the presence of a sylvatic cycle of this disease, making it a serious public health problem worldwide ${ }^{1,5,14}$. Having a mosquito as a vector makes YF hard to be eradicated, justifying why it is essential to act on vector control measures ${ }^{14,37}$.

In 1927, the yellow fever virus strain Asibi isolated from a patient in Ghana was used to formulate the first vaccine. The Asibi strain underwent serial passages in chicken tissue cultures to be attenuated for human use as a vaccine, named the $17 \mathrm{D}$ vaccine. There are two types of sub-strains obtained from the 17D vaccine, the 17DD and 17D-204. The 17D strain was first used in Brazil in 1937 for vaccination purposes, and since then The Oswald Cruz Foundation has produced the yellow fever 17DD (YF-17D) vaccine. To produce the 17DD vaccine, a sample of the yellow fever virus is inoculated into pathogens-free embryonated chicken eggs, as recommended by the $\mathrm{WHO}^{14,18}$.

Since its development in 1930, the YF-17D vaccine has been very effective as a preventive action, inducing the production of neutralizing antibodies directed against the viral envelope protein. Several vaccination strategies have been implemented, including YF vaccination in children's routine vaccination calendar, campaigns and providing vaccination coverage to travelers visiting yellow fever risk zones. In addition to vaccination, vector control is imperative and is also classified as a preventive action. Nevertheless, the yellow fever virus can also be transmitted between humans by the Aedes mosquito, the urban vector, 
resulting in urban epidemics. Therefore, yellow fever surveillance that includes humans, animals (other primate hosts) and vectors deserves special attention in Brazil, especially in the Southeast and Midwest regions ${ }^{14,19,20}$.

Between 2008 and 2009, the transmission of wild yellow fever occurred in Sao Paulo and Rio Grande do Sul (Southeastern and Southern Brazilian States, respectively). These cases of YF were characterized by their occurrence in a wide geographic area in which population had no history of vaccination. In this period, more than 22 million doses of the vaccine were distributed, and the population was alerted to the possibility of vaccine-related adverse events. The Brazilian health services detected and notified 112 severe cases, of which 56 had a causal association with the vaccine. Most of the confirmed adverse events were associated with the vaccine: 47 cases (84\%) had acute neurotropic disease and all of them recovered; the other nine cases were classified as acute viscerotropic disease and $\operatorname{died}^{50}$.

YF eradication constitutes a global challenge. The vaccine plays an important role because it provides longterm humoral immunity ${ }^{50}$. Therefore, this long-term immunogenicity is very helpful and reduces the morbidity and mortality of YF disease, since there is no specific treatment for this disease to date ${ }^{50}$.

According to the WHO, a single dose of the vaccine is still very effective and safe, providing long-lasting protection against YFV, and there are not many reports on YF cases related to vaccination failure ${ }^{14,26,33,51,52}$. However, some adverse effects have been reported, although they were all mild reactions that can also occur with other types of vaccines ${ }^{14,52}$.

Another very important action is to emphasize the importance of vaccinating travelers going to endemic areas, such as Africa and South America countries and encourage YF vaccination in these regions, where the mosquito and YF are endemic ${ }^{26,52}$.

According to Shearer et $a l^{26}$, vaccination coverage has increased over the last 50 years due the extensive vaccination campaigns, but it is still not enough to eliminate $\mathrm{YFV}^{53}$. Moreover, to help some countries in Africa that have faced recent YF outbreaks, in June 2017 the WHO recommended the use of fractional doses of the YF vaccine, if there is a chance of running out of the full vaccine dose $\mathrm{e}^{54}$ for the vaccination coverage of the population. However, the recommended fractional dose should be above 1,000 UI, and it should be used only to avoid the risk of YF spread, providing a one-year protection period ${ }^{53,54}$. It is only a palliative action in cases of low amounts of the vaccine and during outbreaks ${ }^{53,54}$. For this reason, the WHO has been stimulating new discoveries using viral genome sequencing to improve vaccines ${ }^{15}$, and some studies have shown that polyclonal antibody therapies are very effective against many viruses ${ }^{55}$.

\section{CONCLUSION}

As a viral disease with a huge impact, constituting a global public health concern, YF remains poorly studied $^{14,33,53}$. Some reports indicate that genetic variations of the disease may occur ${ }^{27}$. Other aspects that make yellow fever a challenging disease are its similarity with other hemorrhagic fevers (other Flaviviruses, leptospirosis, malaria), the sharing of the same endemics tropical areas, and the concomitance of diseases such as the ones caused by other arboviruses ${ }^{3,41,56}$. These aspects can delay the diagnosis and management of patients including adequate treatment and prevention measures.

Endemic areas would greatly benefit from more costeffective and efficient YF assays to control YF infection ${ }^{4}$. These could prevent outbreaks not only in endemic countries, but also in other territories visited by travelers coming from endemic areas ${ }^{4}$. Unfortunately, serological diagnostic methods are not very accurate due the low levels of circulating immunoglobulins and the high rate of cross-reactions between arboviruses in serology. Thus, having access to a faster differential diagnosis can help to implement the correct treatment and preventive measures $^{3,4,27}$.

Even though yellow fever is a disease that has spread along the years throughout tropical countries, it still requires more studies in some areas of medical specialization for instance, in nephrology, as there is a scarcity of studies on the kidney involvement in yellow fever. The kidney is a very complex organ and its malfunction leads to YF severe forms, in some cases, requiring renal replacement therapy ${ }^{44}$.

The scarcity of studies on yellow fever-induced renal tissue damage can be associated with the non-viral replication in kidney tissues ${ }^{42}$. Moreover, several cases have shown a variety of histological findings related to kidney damage, such as interstitial nephritis, tubular necrosis, interlobular thrombosis in kidney vessels, hemorrhage and adrenal gland ischemic necrosis ${ }^{21,30,36,42}$.

Although the yellow fever virus cannot be completely eradicated due to the existence of a sylvatic cycle, it can be prevented if people from endemic areas and travelers to risk areas are vaccinated and actions are taken to control the urban vector, the Aedes mosquito ${ }^{19,20,53}$. These simple actions can at least prevent the spread of YF disease and new outbreaks since the vaccination, to date, is the only available action against yellow fever ${ }^{53,54}$. History shows that every time the vaccination was neglected in the past, new cases of YF disease resurfaced ${ }^{27}$ making it necessary to use fractional doses of 
the vaccine, which unfortunately does not provide longterm protection ${ }^{53,54}$. Moreover, molecular biology studies using virus-like proteins (VLPs) could be another source for vaccine production, which may show fewer side effects, since VLPs do not contain viral genetic material ${ }^{56}$.

Therefore, the spread of yellow fever disease can be controlled. However, once the disease is established, it is almost impossible to predict how severe it will be, especially because its first symptoms can mimic a number of respiratory, digestive and urinary non-severe infections ${ }^{4,33,36}$. So far, the treatment for this disease consists mainly of providing intensive support ${ }^{33,47,53}$. The impact on important organs such as the liver and the kidneys can be fatal ${ }^{33}$ and will constitute a burden to health care costs. For this reason, we suggest that more studies on the kidney involvement in yellow fever and the early diagnosis of kidney damage should be carried out to minimize the most feared outcome, i.e., death, since the currently existing diagnostic tools neither help to avoid the severe stages of the disease $^{4}$, nor minimize the economic impact of YF sequelae.

\section{CONFLICT OF INTERESTS}

The authors declare no conflict of interests.

\section{REFERENCES}

1. Mansuy JM, Lhomme S, Cazabat M, Pasquier C, Martin-Blondel G, Izopet J. Detection of Zika, dengue and chikungunya viruses using single-reaction multiplex real-time RT-PCR. Diagn Microbiol Infect Dis. 2018;92:284-7.

2. Domingo C, Patel P, Yillah J, Weidmann M, Méndez JA, Nakouné ER, et al. Advanced yellow fever virus genome detection in point-of-care facilities and reference laboratories. J Clin Microbiol. 2012;50:4054-60.

3. Higuera A, Ramírez JD. Molecular epidemiology of dengue, yellow fever, Zika and Chikungunya arboviruses: an update. Acta Trop. 2019;190:99-111.

4. Stock NK, Escadafal C, Achazi K, Cissé M, Niedrig M. Development and characterization of polyclonal peptide antibodies for the detection of Yellow fever virus proteins. J Virol Methods. 2015;222:110-6.

5. Wu W, Wang J, Yu N, Yan J, Zhuo Z, Chen M, et al. Development of multiplex real-time reverse-transcriptase polymerase chain reaction assay for simultaneous detection of Zika, dengue, yellow fever, and chikungunya viruses in a single tube. J Med Virol. 2018;90:1681-6.

6. Aubry F, Nougairède A, Gould EA, de Lamballerie X. Flavivirus reverse genetic systems, construction techniques and applications: a historical perspective. Antiviral Res. 2015;114:67-85.
7. Bozzacco L, Yi Z, Andreo U, Conklin CR, Li MM, Rice CM, MacDonald MR. Chaperone-assisted protein folding is critical for yellow fever virus NS3/4A cleavage and replication. J Virol. 2016;90:3212-28.

8. Klitting R, Fischer C, Drexler JF, Gould EA, Roiz D, Paupy C, de Lamballerie X. What does the future hold for yellow fever virus? (II). Genes (Basel). 2018;9:E425.

9. Fernandez-Garcia MD, Meertens L, Chazal M, Hafirassou ML, Dejarnac O, Zamborlini A, et al. Vaccine and wild-type strains of yellow fever virus engage distinct entry mechanisms and differentially stimulate antiviral immune responses. MBio. 2016;7:e01956-15.

10. Rezende IM, Sacchetto L, Munhoz de Mello E, Alves PA, Iani FC, Adelino TE, et al. Persistence of yellow fever virus outside the Amazon Basin, causing epidemics in Southeast Brazil, from 2016 to 2018. PLoS Neg1 Trop Dis. 2018;12:e0006538.

11. Monath TP, Vasconcelos PF. Yellow fever. J Clin Virol. 2015;64:160-73.

12. Domingo C, Charrel RN, Schmidt-Chanasit J, Zeller H, Reusken C. Yellow fever in the diagnostics laboratory. Emerg Microbes Infect. 2018;7:129.

13. Barbosa CM, Di Paola N, Cunha MP, Rodrigues-Jesus MJ, Araújo $\mathrm{DB}$, Silveira VB, et al. Yellow fever virus RNA in urine and semen of convalescent patient, Brazil. Emerg Infect Dis. 2018;24:176-8.

14. Beasley DW, McAuley AJ, Bente DA. Yellow fever virus: genetic and phenotypic diversity and implications for detection, prevention and therapy. Antiviral Res. 2015;115:48-70.

15. Pestana CP, Lawson-Ferreira R, Lessa-Aquino C, Leal ML, Freire MS, Homma A, et al. Sanger-based sequencing technology for yellow fever vaccine genetic quality control. J Virol Methods. 2018;260:82-7.

16. Douam F, Soto Albrecht YE, Hrebikova G, Sadimin E, Davidson C, Kotenko SV, et al. Type III interferon-mediated signaling is critical for controlling live attenuated yellow fever virus infection in vivo. MBio. 2017;8:e0819-17.

17. Saavedra M. Early-life disease exposure and occupational status: the impact of yellow fever during the $19^{\text {th }}$ century. Explor Econ Hist. 2017;64:62-81.

18. Manso PP, Dias de Oliveira BC, Carvalho de Sequeira P, Rodrigues Maia de Souza Y, Santos Ferro JM, Silva IJ, et al. Kinetic study of yellow fever 17DD viral infection in Gallus gallus domesticus embryos. PLoS One. 2016;11:e0155041.

19. Romano AP, Costa ZG, Ramos DG, Andrade MA, Jayme VS, Almeida MA, et al. Yellow fever outbreaks in unvaccinated populations, Brazil, 2008-2009. PLoS Negl Trop Dis. 2014;8:e2740.

20. Shearer FM, Longbottom J, Browne AJ, Pigott DM, Brady OJ, Kraemer MU, et al. Existing and potential infection risk zones of yellow fever worldwide: a modelling analysis. Lancet Glob Health. 2018;6:e270-8. 
21. Cavalcante KR, Tauil PL. Risk of re-emergence of urban yellow fever in Brazil. Epidemiol Serv Saúde. 2017;26:617-20.

22. Selemane I. Epidemiological monitoring of the last outbreak of yellow fever in Brazil: an outlook from Portugal. Travel Med Infect Dis. 2019;28:46-51.

23. Possas C, Lourenço-de-Oliveira R, Tauil PL, Pinheiro FP, Pissinatti A, Cunha RV, et al. Yellow fever outbreak in Brazil: the puzzle of rapid viral spread and challenges for immunisation. Mem Inst Oswaldo Cruz. 2018;113:e180278.

24. Mir D, Delatorre E, Bonaldo M, Lourenço-de-Oliveira R, Vicente AC, Bello G. Phylodynamics of yellow fever virus in the Americas: new insights into the origin of the 2017 Brazilian outbreak. Sci Rep. 2017;7:7385.

25. World Health Organization. Immunization, vaccines and biologicals: yellow fever. [cited 2019 Jun 24]. Available from: https://www.who.int/immunization/diseases/yellow_fever/en/

26. Shearer FM, Moyes CL, Pigott DM, Brady OJ, Marinho F, Deshpande A, et al. Global yellow fever vaccination coverage from 1970 to 2016: an adjusted retrospective analysis. Lancet Infect Dis. 2017;17:1209-17.

27. Ingelbeen B, Weregemere NA, Noel H, Tshapenda GP, Mossoko M, Nsio J, et al. Urban yellow fever outbreak-Democratic Republic of the Congo, 2016: towards more rapid case detection. PLoS Negl Trop Dis. 2018;12:e0007029.

28. Hanley KA, Monath TP, Weaver SC, Rossi SL, Richman RL, Vasilakis N. Fever versus fever: the role of host and vector susceptibility and interspecific competition in shaping the current and future distributions of the sylvatic cycles of dengue virus and yellow fever virus. Infect Genet Evol. 2013;19:292-311.

29. Chippaux JP, Chippaux A. Yellow fever in Africa and the Americas: a historical and epidemiological perspective. J Venom Anim Toxins Incl Trop Dis. 2018;24:20.

30. Fernandes NC, Cunha MS, Guerra JM, Réssio RA, Cirqueira CS, Iglezias SD, et al. Outbreak of yellow fever among nonhuman primates, Espirito Santo, Brazil, 2017. Emerg Infect Dis. 2017;23:2038-41.

31. Tretyakova I, Nickols B, Hidajat R, Jokinen J, Lukashevich IS, Pushko P. Plasmid DNA initiates replication of yellow fever vaccine in vitro and elicits virus-specific. Virology. 2014;468470:28-35.

32. Brasil. Ministério da Saúde. Ministério da Saúde atualiza casos de febre amarela. Brasília: Ministério da Saúde; 2018. [cited 2019 Jun 24]. Available from: http://portalms.saude.gov.br/ noticias/agencia-saude/42422-ministerio-da-saude-atualizacasos-de-febre-amarela-30-jan

33. World Health Organization. Vaccines and vaccination against yellow fever. WHO Position Paper - June 2013. Wkly Epidemiol Rec. 2013;88:269-83.

34. World Health Organization. Emergencies preparedness, response: yellow fever: a current threat. [cited 2019 Jun 24]. Available from: https://www.who.int/csr/disease/yellowfev/impact1/en/
35. Klitting R, Roth L, Rey FA, de Lamballerie X. Molecular determinants of yellow fever virus pathogenicity in Syrian golden hamsters: one mutation away from virulence. Emerg Microb Infect. 2018;7:51.

36. Maciel GV, Tavares MC, Pereira LS, Silva GL, Oliveira NR, Paulino Júnior E, et al. Disseminated mycosis in a patient with yellow fever. Autops Case Rep. 2018;8:e2018038.

37. Escadafal C, Faye O, Sall AA, Faye O, Weidmann M, Strohmeier $\mathrm{O}$, et al. Rapid molecular assays for the detection of yellow fever virus in low-resource settings. PLoS Negl Trop Dis. 2014;8:e2730.

38. Ibrahim F, Thio TH, Faisal T, Neuman M. The application of biomedical engineering techniques to the diagnosis and management of tropical diseases: a review. Sensors (Basel). 2015;15:6947-95.

39. Ribeiro M, Antunes CM. Febre amarela: estudo de um surto. Rev Soc Bras Med Trop. 2009;42:523-31.

40. Zarei M. Infectious pathogens meet point-of-care diagnostics. Biosens Bioelectron. 2018;106:193-203.

41. Priya SP, Sakinah S, Sharmilah K, Hamat RA, Sekawi Z, Higuchi A, et al. Leptospirosis: molecular trial path and immunopathogenesis correlated with dengue, malaria and mimetic hemorrhagic infections. Acta Trop. 2017;176:206-23.

42. Engelmann F, Josset L, Girke T, Park B, Barron A, Dewane J, et al. Pathophysiologic and transcriptomic analyses of viscerotropic yellow fever in a rhesus macaque model. PLoS Negl Trop Dis. 2014;8:e3295.

43. Daher EF, Silva Junior GB. Nefropatia nas doenças tropicais. In: Riella MC, editor. Princípios de nefrologia e distúrbios hidreletrolíticos. $6^{\mathrm{a}}$ ed. Rio de Janeiro: Guanabara-Koogan; 2018. p.553-81.

44. Daher EF, Barros E, Silva Junior GB. Nefrologia tropical. São Paulo: Balieiro; 2019.

45. El-Khoury JM. The search for a high-sensitiviy creatinine assay: is symmetric dimethylarginine ready for prime time in humans? Clin Lab News. 2018;44:18-21.

46. Silva RA, Bezerra MX, Souza Neto VL, Mororó DD, Andrade IC. Children with kidney diseases: association between nursing diagnoses and their diagnostic indicators. Acta Paul Enferm. 2017;30:73-9.

47. Freitas CS, Higa LM, Sacramento CQ, Ferreira AC, Reis PA, Delvecchio R, et al. Yellow fever virus is susceptible to sofosbuvir both in vitro and in vivo. PLoS Negl Trop Dis. 2019;13:e007072.

48. Ferreira AC, Reis PA, Freitas CS, Sacramento CQ, Villas Bôas Hoelz L, Bastos MM, et al. Beyond members of the Flaviviridae family, sofosbuvir also inhibits chikungunya virus replication. Antimicrob Agents Chemother. 2019;63:e01389-18.

49. Islan GA, Durán M, Cacicedo ML, Nakazato G, Kobayashi RK, Martinez DS, et al. Nanopharmaceuticals as a solution to neglected diseases: is it possible? Acta Trop. 2017;170:16-42. 
50. Costa ZG, Romano AP, Elkhoury AN, Flannery B. Evolução histórica da vigilância epidemiológica e do controle da febre amarela no Brasil. Rev Pan-Amaz Saude. 2011;2:11-26.

51. Lindsey NP, Horiuchi KA, Fulton C, Panella AJ, Kosoy OI, Velez JO, et al. Persistence of yellow fever virus-specific neutralizing antibodies after vaccination among US travellers. J Travel Med. 2018;25:tay 108.

52. Lindsey NP, Schroeder BA, Miller ER, Braun MM, Hinckley AF, Marano N, et al. Adverse event reports following yellow fever vaccination. Vaccine. 2008;26:6077-82.

53. Douam F, Ploss A. Yellow fever virus: knowledge gaps impeding the fight against an old foe. Trends Microbiol. 2018;26:913-28.
54. Vannice K, Wilder-Smith A, Hombach J. Fractional-dose yellow fever vaccination: advancing the evidence base. N Engl J Med. 2018;379:603-5.

55. Dixit R, Herz J, Dalton R, Booy R. Benefits of using heterologous polyclonal antibodies and potential applications to new and undertreated infectious pathogens. Vaccine. 2016;34:1152-61

56. Krol E, Brzuska G, Szewczyk B. Production and Biomedical Application of Flavivirus-like Particles. Trends Biotechnol. In Press 2019. 